\title{
Pancreatic stone protein as an early biomarker predicting mortality in a prospective cohort of patients with sepsis requiring ICU management
}

Yok-Ai Que ${ }^{1}$, Frederik Delodder ${ }^{1}$, Idris Guessous ${ }^{2,3}$, Rolf Graff ${ }^{4}$, Martha Bain ${ }^{4}$, Thierry Calandra ${ }^{5}$, Lucas Liaudet ${ }^{1}$ and Philippe Eggimann ${ }^{1 *}$

\begin{abstract}
Introduction: Biomarkers, such as C-reactive protein [CRP] and procalcitonin [PCT], are insufficiently sensitive or specific to stratify patients with sepsis. We investigate the prognostic value of pancreatic stone protein/ regenerating protein (PSP/reg) concentration in patients with severe infections.

Methods: PSP/reg, CRP, PCT, tumor necrosis factor-alpha (TNF- $\alpha$ ), interleukin 1 beta (IL1- $\beta$ ), IL-6 and IL-8 were prospectively measured in cohort of patients $\geq 18$ years of age with severe sepsis or septic shock within 24 hours of admission in a medico-surgical intensive care unit (ICU) of a community and referral university hospital, and the ability to predict in-hospital mortality was determined.

Results: We evaluated 107 patients, 33 with severe sepsis and 74 with septic shock, with in-hospital mortality rates of $6 \%(2 / 33)$ and $25 \%(17 / 74)$, respectively. Plasma concentrations of PSP/reg (343.5 vs. $73.5 \mathrm{ng} / \mathrm{ml}, \mathrm{P}<0.001)$, PCT (39.3 vs. $12.0 \mathrm{ng} / \mathrm{ml}, \mathrm{P}<0.001)$, IL-8 (682 vs. $184 \mathrm{ng} / \mathrm{ml}, \mathrm{P}<0.001)$ and IL-6 (1955 vs. $544 \mathrm{pg} / \mathrm{ml}, \mathrm{P}<0.01$ ) were significantly higher in patients with septic shock than with severe sepsis. Of note, median PSP/reg was $13.0 \mathrm{ng} / \mathrm{ml}$ (IQR: 4.8) in 20 severely burned patients without infection. The area under the ROC curve for PSP/reg (0.65 [95\% Cl: 0.51 to 0.80$]$ ]) was higher than for CRP (0.44 [0.29 to 0.60$]$ ), PCT 0.46 [0.29 to 0.61]), IL-8 (0.61 [0.43 to 0.77]) or IL-6 (0.59 [0.44 to 0.75$])$ in predicting in-hospital mortality. In patients with septic shock, PSP/reg was the only biomarker associated with in-hospital mortality $(P=0.049)$. Risk of mortality increased continuously for each ascending quartile of PSP/reg.

Conclusions: Measurement of PSP/reg concentration within 24 hours of ICU admission may predict in-hospital mortality in patients with septic shock, identifying patients who may benefit most from tailored ICU management.
\end{abstract}

\section{Introduction}

Despite significant improvements in clinical management, including systematic multimodal approaches [1], severe forms of infections, such as severe sepsis and septic shock, are the leading causes of mortality in patients admitted to the intensive care unit (ICU) [2-4]. Over the last two decades, several promising therapeutic strategies designed to specifically target pathogen or host-related mediators involved in the septic process have failed to reduce mortality [5-7], and this failure is due, in part, to

\footnotetext{
* Correspondence: philippe.eggimann@chuv.ch

'Department of Intensive Care Medicine, University Hospital Medical Center (CHUV) and University of Lausanne, Rue du Bugnon 46, CH-1011 Lausanne, Switzerland

Full list of author information is available at the end of the article
}

the heterogeneity of both microbial agents and host inflammatory responses [8]. Since therapeutic strategies should be adapted to each individual patient, the identification of patients who are at high risk of death and who might benefit most from early and aggressive treatment would represent a critical step toward such tailored management [9]. Serum biomarkers may assist clinicians in risk stratification and decision-making processes [10]. An ideal biomarker in patients with sepsis should improve early diagnosis and predict early deterioration toward organ failure and eventually death, thereby identifying patients requiring additional aggressive treatments [11]. Owing to a lack of specificity or sensitivity or both (for example, C-reactive protein (CRP) and procalcitonin
C Biomed Central

() 2012 Que et al.; licensee BioMed Central Ltd. This is an open access article distributed under the terms of the Creative Commons Attribution License (http://creativecommons.org/licenses/by/2.0), which permits unrestricted use, distribution, and reproduction in any medium, provided the original work is properly cited. 
(PCT) $[10,12])$ or to a narrow time window of expression (for example, interleukin-6 (IL-6) and IL-8 [8]), currently used biomarkers do not fulfill such requirements. Therefore, further efforts are needed to identify novel sepsis biomarkers.

Pancreatic stone protein/regenerating protein (PSP/reg) is constitutively secreted by pancreatic acinar cells into pancreatic juice along with zymogens and is also secreted by subsets of intestinal and gastric cells [13]. Although its precise physiological roles remain only partly defined, it appears to have protective functions by promoting cellular proliferative responses during beta-cell regenerative processes and epithelial repair [13]. PSP/reg is upregulated during acute and chronic pancreatitis; in animals, its expression may be induced by stress conditions in the absence of any pancreatic inflammation. In a recent clinical study, serum concentrations of PSP/reg were found to be markedly elevated after trauma, and PSP/reg concentrations showed a close correlation with the severity of posttrauma infection [14]. Furthermore, PSP/reg was found to bind to polymorphonuclear cells and seemed to induce or maintain their activation or both; thus, PSP/reg might serve as an acute-phase protein [14].

We therefore hypothesized that PSP/reg concentration may represent a potential biomarker of sepsis-related inflammation. To address this hypothesis, we prospectively measured plasma concentrations of PSP/reg within 24 hours of ICU admission in 107 patients with clinically diagnosed forms of severe infections. (Some of the results of these studies have been reported in the form of an abstract [15].)

\section{Materials and methods Patient population}

This study was performed between February 2008 and June 2010 in a 32-bed adult medico-surgical ICU of a community and referral university hospital. Patients who were at least 18 years old were evaluated within 24 hours of ICU admission for severe sepsis or septic shock. Owing to organizational constraints, inclusion was prospective but could not be strictly consecutive. The study was approved by the Institutional Review Board (Commission cantonale [VD] d'éthique de la recherche sur l'être humain, Lausanne, Switzerland). Written informed consent was obtained from patients or relatives. Infections, sepsis, severe sepsis, and septic shock were defined according to commonly used criteria [16] (Additional file 1). Patients were followed until death or discharge from the hospital. In-hospital mortality was the primary endpoint.

\section{Data collection}

In addition to recording clinical variables collected from the computerized information system (Metavision; IMDsoft, Tel Aviv, Israel), we recorded the age, sex, admission category, origin (home, emergency room, or ward), and McCabe score of each patient [17]. Severity of illness was evaluated on the first day in the ICU by using the Simplified Acute Physiology Score (SAPS) II [18] and III [19] and the Acute Physiology and Chronic Health Evaluation II (APACHE II) score [20]. Organ dysfunction was evaluated by the Sequential Organ Failure Assessment (SOFA) score [21]. Severe comorbidities were described by using definitions of the APACHE II score and SAPS II and III.

\section{Measurement of plasma biomarker concentrations}

At the time of enrollment, heparinized plasma was obtained from each patient for measurements of biomarkers. (Detailed measurement protocols are presented in Additional file 1.) PSP/reg was quantified by using an isoform-specific enzyme-linked immunosorbent assay as described previously [14]. Briefly, plasma samples were incubated with plates precoated with guinea pig anti-PSP/ reg antibody. Rabbit anti-PSP/reg was added and subsequently detected by phosphatase-conjugated anti-rabbit immunglobulin G. This assay had a detection limit of less than $0.1 \mathrm{ng} / \mathrm{mL}$ and an inter-plate variance of less than $10 \%$ [14].

\section{Statistical analysis}

Continuous variables are reported as mean and standard deviation (SD) or medians and interquartile ranges (IQRs) as indicated. Categorical variables are reported as frequencies and percentages. Because the distributions of the biomarkers were skewed, continuous variables between severity of infection or between survivors and non-survivors were compared by using non-parametric two-sided Wilcoxon-Mann-Whitney rank sum tests. APACHE II, SAPS II and III, and SOFA scores are expressed as mean and SD.

Receiver operating characteristic (ROC) curves using concentrations of acute-phase proteins (CRP, PCT, and $\mathrm{PSP} / r e g$ ), pro-inflammatory cytokines (IL-6, IL-8, and IL10 ), and acute severity scores (APACHE II and SAPS II and III) as independent variables and mortality as a dependent variable were computed first for the entire population and then specifically for patients with septic shock only. From these curves, we computed areas under the curve (AUCs) and 95\% confidence intervals (CIs) to assess the discrimination ability of each marker for predictive purposes. Multiple logistic regression analysis and age-adjusted predicted hospital mortality (expressed as age-adjusted beta regression coefficients) were used to assess the relationship (for example, linearity and distribution) between biomarker concentrations and in-hospital mortality. Finally, we estimated the odds ratios (ORs) for mortality and trends across biomarker quartiles. All $P$ values were two-sided, and statistical significance was set 
at a $P$ value of less than 0.05 . We used Stata (version 11.2; StataCorp LP, College Station, TX, USA) for data processing and analyses.

\section{Results}

\section{Patient characteristics}

From February 2008 to June 2010, 177 patients were prospectively screened (Additional file 2, Figure S1); of these, 25 (14\%) declined consent and 18 (10\%) died before consent could be obtained. We included 107 patients: $33(30 \%)$ with severe sepsis and 74 (70\%) with septic shock (Table 1). There were more males than females in each subgroup. Sixty-one (57\%) and 46 (43\%) patients presented with community-acquired and nosocomial infections, respectively. Over $75 \%$ of patients had pulmonary or abdominal infections, and high percentages were infected with Streptococcus pneumoniae (18.7\%) or Escherichia coli $(21.5 \%)$. The overall in-hospital mortality rates were $20.5 \%$, $9 \%$ for patients with severe sepsis, and $25.7 \%$ for patients with septic shock. Most patients had at least one comorbid condition, but fewer than $14 \%$ had McCabe scores predicting rapidly fatal outcome.

\section{Plasma levels of CRP, PCT, PSP/reg, and inflammatory} cytokines in patients with severe sepsis and septic shock Plasma concentrations of the various biomarkers in relation to the severity of infection (severe sepsis or septic shock) are presented in Table 2 and in Figure S2 of Additional file 3 . In comparison with the concentrations of $\mathrm{CRP}$, those of the acute-phase proteins PCT and PSP/reg and the pro-inflammatory cytokines IL- 6 and IL- 8 were significantly higher in patients with septic shock than in patients with severe sepsis, and the median PSP/reg concentration was about five times higher in patients with septic shock (343.5 $\mathrm{ng} / \mathrm{L})$ than in patients with severe sepsis $(73.5 \mathrm{ng} / \mathrm{L})$. As expected, the acute severity scores (APACHE II and SAPS II and III) were significantly higher in patients with septic shock than in those with severe sepsis.

$\mathrm{PSP} /$ reg was further measured in the plasma of burned patients who were previously admitted to our ICU and in whom trace element supplementation resulted in improved clinical outcome, including fewer pulmonary infections and better wound healing [22]. In these 20 patients with severe non-infectious inflammation (mean age of $43 \pm 16$ years, mean total surface body area burned of $45 \% \pm 22 \%$, and median SAPS II of 32 and IQR of 14 ), the median PSP/reg within the first 24 hours of admission was $13.0 \mathrm{ng} / \mathrm{mL}$ (IQR of 4.8). Figure S3 of Additional file 4 displays the individual values of $\mathrm{PSP} / \mathrm{reg}$ in these patients compared with those with severe sepsis and septic shock.
Association between plasma levels of CRP, PCT, PSP/reg, and inflammatory cytokines and in-hospital mortality We assessed the relationship between the plasma concentrations of CRP, PCT, and PSP/reg; the concentrations of inflammatory cytokines; the number of leukocytes; severity scores (APACHE II, SAPS II and III, and SOFA); and inhospital mortality in patients with severe sepsis or septic shock (Table 3 and Additional file 1, Table S1). Overall, regardless of severity, PSP/reg concentrations and SAPS III scores were the only variables that differed significantly between survivors and non-survivors (Table 3). Despite their association with severity, IL-6, IL-8, PCT, APACHE II, and SAPS II were not associated with mortality. Among patients with septic shock (Additional file 1, Table S1), $\mathrm{PSP} /$ reg remained the only biomarker significantly associated with mortality $(P=0.049)$.

\section{Biomarkers and severity scores as predictors of in- hospital mortality}

We used AUC analysis to further explore the capacity of each parameter to predict mortality at ICU admission (Figure 1 and Additional file 1, Table S2) within our particular population of patients admitted with a diagnosis of severe sepsis or septic shock. ROCs were computed for the entire patient cohort (Figure 1a) and for patients with septic shock (Figure 1b). When applied to the whole population, PSP/reg, IL-8, and IL-6 yielded the highest discriminative value with AUCs (95\% CIs) of 0.65 (0.51 to 0.80 ), 0.61 (0.43 to 0.77 ), and 0.59 (0.44 to 0.75$)$, respectively. In contrast, the AUCs (95\% CIs) of CRP and PCT were 0.44 (0.29 to 0.60$)$ and $0.46(0.29$ to 0.61$)$, respectively (Figure 1a and Additional file 1, Table S2). Similar patterns and AUC values were observed when the analysis was restricted to patients with septic shock (Figure 1b and Additional file 1, Table S2).

$\mathrm{PSP} /$ reg showed a more uniform and linear distribution than other biomarkers throughout the range of probability of in-hospital mortality (Figure 2a, b). Only seven patients with septic shock (9.5\%) presented with IL-6 concentrations in the three highest quartiles in comparison with 20 (27\%) for PSP/reg (Figure 2b).

The age-adjusted beta regression coefficients - that is, the change in probability of in-hospital mortality per standard unit (one SD) change in biomarker concentration were 0.16 (SD of 0.07 ) per $100 \mathrm{ng} / \mathrm{mL}$ increase of $\mathrm{PSP} / \mathrm{reg}$ $(P=0.03), 0.17$ (SD of 0.10$)$ per $50 \mathrm{ng} / \mathrm{mL}$ increase of IL-6 $(P=0.08)$, and -0.00076 (SD of 0.0587$)$ per $10 \mathrm{ng} / \mathrm{mL}$ increase of PCT $(P=0.99)$. When restricted to patients with septic shock, the age-adjusted beta regression coefficients were 0.16 (SD of 0.08 ) per $100 \mathrm{ng} / \mathrm{mL}$ increase of $\mathrm{PSP} /$ reg $(P=0.048), 0.15$ (SD of 0.10$)$ per $50 \mathrm{ng} / \mathrm{mL}$ increase of IL-6 $(P=0.15)$, and -0.0167 (SD of 0.062$)$ per $10 \mathrm{ng} / \mathrm{mL}$ increase of PCT $(P=0.79)$. 
Table 1 Patient characteristics, by sepsis severity $(n=107)$

\begin{tabular}{|c|c|c|c|}
\hline Patient characteristic & $\begin{array}{c}\text { All } \\
(n=107)\end{array}$ & $\begin{array}{c}\text { Severe sepsis } \\
\quad(n=33)\end{array}$ & $\begin{array}{l}\text { Septic shock } \\
\quad(n=74)\end{array}$ \\
\hline \multicolumn{4}{|l|}{ Demographics } \\
\hline Age in years, mean $\pm S D$ & $59 \pm 17.5$ & $55 \pm 20$ & $61 \pm 16$ \\
\hline Male/Female & $62 / 45$ & 20/13 & $42 / 32$ \\
\hline \multicolumn{4}{|l|}{ Admission categories } \\
\hline Medical & $72(67 \%)$ & $24(73 \%)$ & $48(65 \%)$ \\
\hline Scheduled surgery & $4(4 \%)$ & $0(0 \%)$ & $4(5 \%)$ \\
\hline Unscheduled surgery & $31(29 \%)$ & $9(27 \%)$ & $22(30 \%)$ \\
\hline \multicolumn{4}{|l|}{ Origin } \\
\hline Community (home/emergency room) & $61(57 \%)$ & $18(54.5 \%)$ & $43(58.1 \%)$ \\
\hline Nosocomial (hospital transfer) & $46(43 \%)$ & $15(45.5 \%)$ & $31(41.9 \%)$ \\
\hline Referral from other hospital & $20(18.7 \%)$ & $5(15.2 \%)$ & $15(20.3 \%)$ \\
\hline Operating room & $3(2.8 \%)$ & $1(3 \%)$ & $2(2.7 \%)$ \\
\hline Ward & $14(13.1 \%)$ & $6(18.2 \%)$ & $8(10.8 \%)$ \\
\hline Intermediate care & $9(8.4 \%)$ & $3(9.1 \%)$ & $6(8.1 \%)$ \\
\hline \multicolumn{4}{|l|}{ Severe comorbidities } \\
\hline Chronic obstructive pulmonary disease & $17(15.8 \%)$ & $5(15.1 \%)$ & $12(16.2 \%)$ \\
\hline Cardiac insufficiency & $16(15 \%)$ & $2(6 \%)$ & $14(18.9 \%)$ \\
\hline Cirrhosis & $8(7.5 \%)$ & $1(3 \%)$ & 7 (9.5\%) \\
\hline End-stage renal disease & $15(14 \%)$ & $3(9 \%)$ & $12(16.2 \%)$ \\
\hline Immunodeficiency ${ }^{a}$ & $13(12.1 \%)$ & $2(6 \%)$ & $11(14.9 \%)$ \\
\hline Insulin-dependent diabetes & $6(5.6 \%)$ & $1(3 \%)$ & $5(6.7 \%)$ \\
\hline \multicolumn{4}{|l|}{ Score, mean \pm SD } \\
\hline APACHE ॥ & $30 \pm 8$ & $27 \pm 86$ & $31 \pm 8$ \\
\hline SAPS $\|$ & $71 \pm 17$ & $65 \pm 16$ & $74 \pm 17$ \\
\hline SAPS III & $76 \pm 18$ & $67 \pm 21$ & $80 \pm 15$ \\
\hline SOFA (day 1) & $11 \pm 3$ & $11 \pm 3$ & $11 \pm 3$ \\
\hline \multicolumn{4}{|l|}{ McCabe score } \\
\hline Non-fatal & $63(59 \%)$ & $22(66.6 \%)$ & $41(55 \%)$ \\
\hline Ultimately fatal ( $<5$ years) & $30(28 \%)$ & $7(21.2 \%)$ & $23(31 \%)$ \\
\hline Rapid fatal ( $<6$ months) & $14(13 \%)$ & $4(12.2 \%)$ & $10(14 \%)$ \\
\hline \multicolumn{4}{|l|}{ Infection sites } \\
\hline Pulmonary & 37 (34.5\%) & $14(42.4 \%)$ & $23(31 \%)$ \\
\hline Abdominal & $38(36 \%)$ & $7(21.2 \%)$ & $31(41.9 \%)$ \\
\hline Bloodstream & $7(6.5 \%)$ & $4(12.1 \%)$ & $3(4.1 \%)$ \\
\hline CNS and ENT & $5(4.6 \%)$ & $2(6.1 \%)$ & $3(4.1 \%)$ \\
\hline Urinary tract & $5(4.6 \%)$ & $2(6.1 \%)$ & $3(4.1 \%)$ \\
\hline Soft tissues & $13(12 \%)$ & $4(12.1 \%)$ & $9(12.1 \%)$ \\
\hline Miscellaneous & $2(1.8 \%)$ & $0(0 \%)$ & $2(2.7 \%)$ \\
\hline \multicolumn{4}{|l|}{ Microbiology } \\
\hline Gram-positive (number of positive blood cultures) & $41(38.3 \%)$ & $17(51.5 \%)$ & $24(32.4 \%)$ \\
\hline Staphylococcus aureus (8) & $8(7.5 \%)$ & $5(15.1 \%)$ & $3(4.1 \%)$ \\
\hline Streptococcus pyogenes (2) & $10(9.3 \%)$ & $2(6.1 \%)$ & $8(10.8 \%)$ \\
\hline Streptococcus pneumoniae (8) & $20(18.7 \%)$ & $8(24.2 \%)$ & $12(16.1 \%)$ \\
\hline Other (2) & $3(2.8 \%)$ & $2(6.1 \%)$ & $1(1.4 \%)$ \\
\hline Gram-negative & $45(42 \%)$ & $13(39.4 \%)$ & $32(43.2 \%)$ \\
\hline Escherichia coli (14) & $23(21.5 \%)$ & $5(15.2 \%)$ & $18(24.3 \%)$ \\
\hline Other Enterobacteriacae (5) & 7 (6.5\%) & $1(3.05 \%)$ & $6(8.1 \%)$ \\
\hline Pseudomonas aeruginosa (5) & $6(5.6 \%)$ & $3(9.05 \%)$ & $3(4.1 \%)$ \\
\hline Other (5) & $9(8.4 \%)$ & $4(12.1 \%)$ & $5(6.7 \%)$ \\
\hline Fungi & $3(2.8 \%)$ & $0(0 \%)$ & $3(4.1 \%)$ \\
\hline
\end{tabular}


Table 1 Patient characteristics, by sepsis severity $(n=107)$ (Continued)

\begin{tabular}{lccc}
\hline Candida albicans (1) & $1(1 \%)$ & $0(0 \%)$ & $1(1.4 \%)$ \\
Other (0) & $2(1.8 \%)$ & $0(0 \%)$ & $2(2.7 \%)$ \\
H1N1 & $1(1 \%)$ & $0(0 \%)$ & $1(1.4 \%)$ \\
$\quad$ Undocumented & $17(15.9 \%)$ & $3(9.1 \%)$ & $14(18.9 \%)$ \\
Outcome & & $3(9 \%)$ & $19(25.7 \%)$ \\
Hospital mortality & $22(20.6 \%)$ & \\
\hline
\end{tabular}

Values are presented as numbers (percentages) of patients unless indicated otherwise. ${ }^{\mathrm{H}} \mathrm{HIV}$, solid organ transplant recipients, hematological malignancies, chronic use of more than $30 \mathrm{mg}$ per day prednisone equivalents. APACHE II, Acute Physiology and Chronic Health Evaluation II; CNS, central nervous system; ENT, ear, nose, and throat; SAPS, Simplified Acute Physiology Score; SD, standard deviation; SOFA, Sequential Organ Failure Assessment.

Moreover, in contrast to IL-6 and PCT, the ageadjusted ORs (95\% CIs) of mortality among patients with septic shock increased continuously across PSP/reg quartiles: PSP/reg OR 1.0 [reference group], 1.5 (0.19 to 10.0 ), 5.1 (0.8 to 32.0), and 6.4 (0.96 to 42.0 ), respectively (test for trend $P=0.02$ ). For IL-6 quartiles, the age-adjusted ORs (95\% CIs) for mortality among patients with septic shock were 1.0 [reference group], 2.0 (0.36 to 10.0$), 1.3(0.23$ to 7.5$)$, and 2.4 (0.45 to 12.0 ), respectively (test for trend $P=0.41$ ), whereas, for $\mathrm{PCT}$, the corresponding values were 1.0 [reference group], 0.4 (0.7 to 2.0), 0.7 (0.16 to 3.1), and 0.4 (0.08 to 1.9 ), respectively (test for trend $P=0.35$ ).

\section{Discussion}

Our results suggest that $\mathrm{PSP} / \mathrm{reg}$, a novel acute-phase protein, measured within 24 hours of ICU admission, may predict the risk of mortality in patients with severe sepsis and septic shock. PSP/reg was identified in patients with pancreatitis and further associated with islet regeneration $[13,23]$. The findings that its expression was not restricted to the pancreas $[24,25]$ and that it can be induced by stress in animals [26] opened the way to investigate its role as a potential acute-phase protein. A recent study in 83 trauma patients reported that PSP/reg concentrations were 15-fold higher from baseline (5 to $15 \mathrm{ng} / \mathrm{mL}$ ) in patients developing septic complications [14].

Our results suggest that $\mathrm{PSP} / \mathrm{reg}$, measured within 24 hours of ICU admission, may be used as a biomarker to identify septic patients at highest risk of death. PSP/reg performed better than CRP and PCT, which are widely used to diagnose infection but which, owing to their poor accuracy in this indication, should not be used to predict disease outcome $[10,12,27,28]$. A similar observation was recently reported in a cohort of 101 patients with ventilator-associated pneumonia [29]. In this cohort, PSP/reg measured after 7 days of mechanical ventilation predicted subsequent organ failure development and, eventually, outcome. A major advantage of

Table 2 Plasma concentrations of biomarkers and severity scores, by sepsis severity

\begin{tabular}{|c|c|c|c|c|c|c|c|}
\hline \multirow[t]{2}{*}{ Biomarker or severity scoring system } & \multicolumn{2}{|c|}{ All $(n=107)$} & \multicolumn{2}{|c|}{ Severe sepsis $(n=33)$} & \multicolumn{2}{|c|}{ Septic shock $(n=74)$} & \multirow[b]{2}{*}{ Test } \\
\hline & Median & IQR & Median & IQR & Median & IQR & \\
\hline \multicolumn{8}{|l|}{ Acute-phase proteins } \\
\hline $\mathrm{CRP}, \mathrm{mg} / \mathrm{L}$ & 253.5 & 155.5 & 218 & 152 & 266 & 158 & 0.35 \\
\hline $\mathrm{PCT}, \mathrm{ng} / \mathrm{mL}$ & 25.12 & 48.98 & 11.96 & 20.94 & 39.25 & 49.99 & $<0.0001$ \\
\hline $\mathrm{PSP} / \mathrm{reg}, \mathrm{ng} / \mathrm{mL}$ & 241.25 & 399.00 & 73.5 & 180.25 & 343.5 & 369 & $<0.0001$ \\
\hline \multicolumn{8}{|l|}{ Cytokines } \\
\hline TNF- $\alpha, p g / m l$ & 2.47 & 7.07 & 1.93 & 7.07 & 2.41 & 6.97 & 0.86 \\
\hline $\mathrm{IL}-1 \beta, \mathrm{pg} / \mathrm{mL}$ & 6.43 & 21.04 & 1.96 & 15.53 & 8.175 & 24.54 & 0.21 \\
\hline $\mathrm{IL}-6, \mathrm{pg} / \mathrm{mL}$ & $1,173.28$ & $6,749.6$ & 544.07 & $1,237.48$ & $1,755.34$ & $14,514.13$ & 0.004 \\
\hline IL-8, pg/mL & 438.95 & $1,804.67$ & 184.15 & 408.72 & 681.775 & $3,273.42$ & 0.0001 \\
\hline IL-10, pg/mL & 149.37 & 672.82 & 76.24 & 239.67 & 199.94 & 706.22 & 0.045 \\
\hline \multicolumn{8}{|l|}{ Other } \\
\hline Leukocytes, G/L & 13.5 & 14.2 & 13.5 & 5.5 & 13.3 & 17.1 & 0.28 \\
\hline APACHE $\|$ & 28 & 14 & 26 & 14 & 29 & 14 & 0.04 \\
\hline SAPS ॥ & 69 & 26 & 62 & 29 & 71 & 27 & 0.02 \\
\hline SAPS III & 76 & 27 & 69 & 28 & 79.5 & 25 & 0.001 \\
\hline SOFA & 11 & 4 & 10 & 5 & 11 & 5 & 0.35 \\
\hline
\end{tabular}

APACHE II, Acute Physiology and Chronic Health Evaluation II; CRP, C-reactive protein; IL, interleukin; IQR, interquartile range; PCT, procalcitonin; PSP/reg, pancreatic stone protein/regenerating protein; SAPS, Simplified Acute Physiology Score; SOFA, Sequential Organ Failure Assessment; TNF- $\alpha$, tumor necrosis factoralpha. 
Table 3 Plasma concentrations of biomarkers and severity scores, by survival status

\begin{tabular}{|c|c|c|c|c|c|}
\hline \multirow[t]{3}{*}{ Biomarker or severity scoring system } & \multicolumn{4}{|c|}{ All $(n=107)$} & \multirow[b]{3}{*}{$P$ value } \\
\hline & \multicolumn{2}{|c|}{ Death $(n=22)$} & \multicolumn{2}{|c|}{ Survival $(n=85)$} & \\
\hline & Median & IQR & Median & IQR & \\
\hline \multicolumn{6}{|l|}{ Acute-phase proteins } \\
\hline $\mathrm{CRP}, \mathrm{mg} / \mathrm{L}$ & 203 & 188 & 266 & 154 & 0.21 \\
\hline $\mathrm{PCT}, \mathrm{ng} / \mathrm{mL}$ & 17.485 & 51.75 & 26.22 & 44.75 & 0.57 \\
\hline $\mathrm{PSP} / \mathrm{reg}, \mathrm{ng} / \mathrm{mL}$ & 397 & 435.9 & 216.1 & 379 & 0.02 \\
\hline \multicolumn{6}{|l|}{ Cytokines } \\
\hline TNF- $\alpha, p g / m l$ & 2.655 & 10.36 & 2.35 & 6.73 & 0.46 \\
\hline$\| \mathrm{L}-1 \beta, \mathrm{pg} / \mathrm{mL}$ & 0.795 & 34.02 & 7.6 & 20.41 & 0.46 \\
\hline $\mathrm{IL}-6, \mathrm{pg} / \mathrm{mL}$ & $2,415.58$ & $16,219.42$ & 790.53 & $6,467.74$ & 0.16 \\
\hline IL-8, pg/mL & 757.775 & $10,597.73$ & 414.88 & $1,597.6$ & 0.11 \\
\hline IL-10, pg/mL & 416.18 & 1393.6 & 136.76 & 494.89 & 0.17 \\
\hline \multicolumn{6}{|l|}{ Other } \\
\hline Leukocytes, G/L & 13.85 & 14.45 & 13.4 & 14.2 & 0.27 \\
\hline APACHE ॥ & 32 & 12 & 27 & 13 & 0.4 \\
\hline SAPS $\|$ & 71.5 & 26 & 68 & 27 & 0.52 \\
\hline SAPS III & 87.5 & 27 & 74 & 25 & 0.01 \\
\hline SOFA & 11 & 6 & 11 & 4 & 0.9 \\
\hline
\end{tabular}

APACHE II, Acute Physiology and Chronic Health Evaluation II; CRP, C-reactive protein; IL, interleukin; IQR, interquartile range; PCT, procalcitonin; PSP/reg, pancreatic stone protein/regenerating protein; SAPS, Simplified Acute Physiology Score; SOFA, Sequential Organ Failure Assessment; TNF- $\alpha$, tumor necrosis factoralpha.

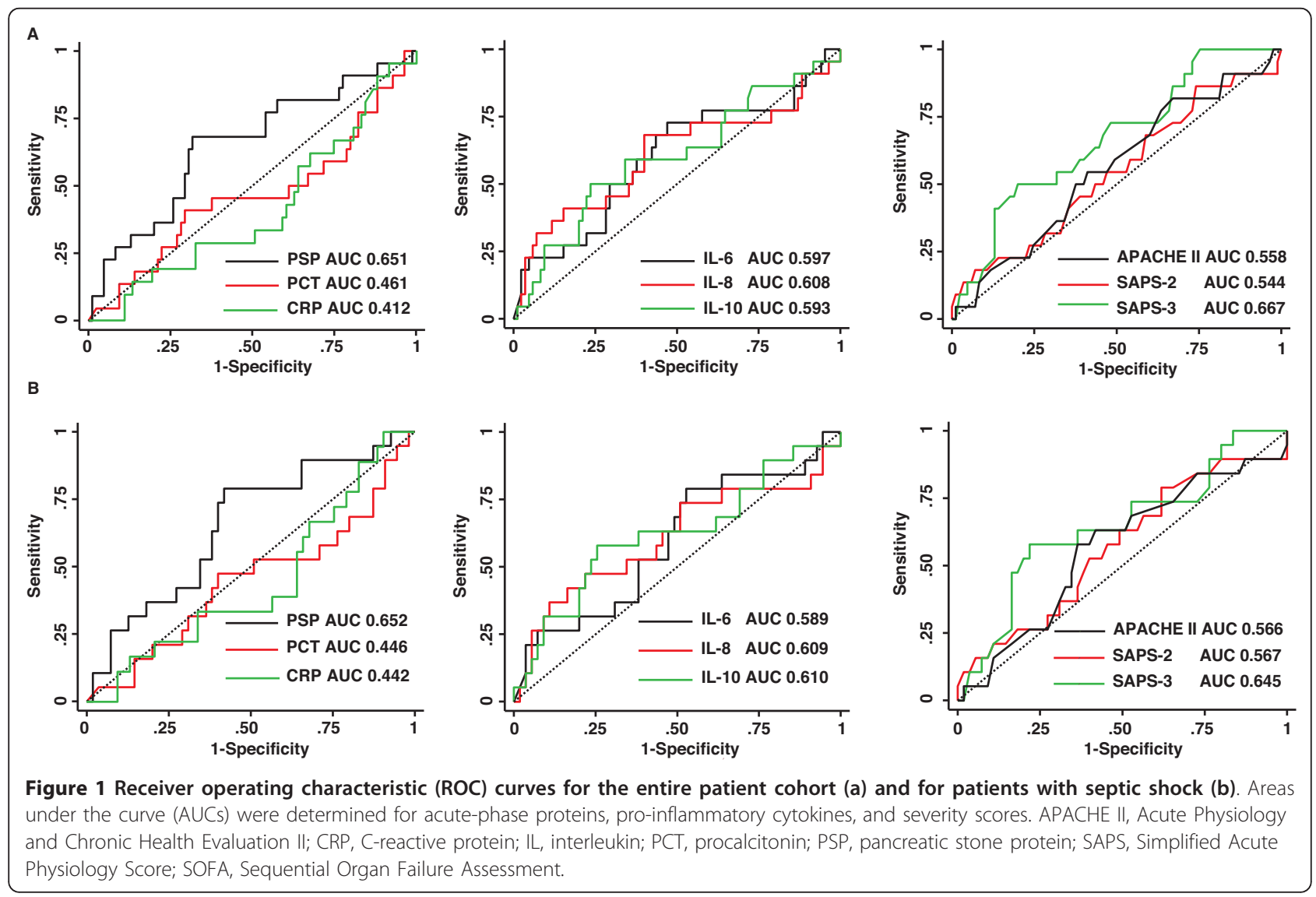




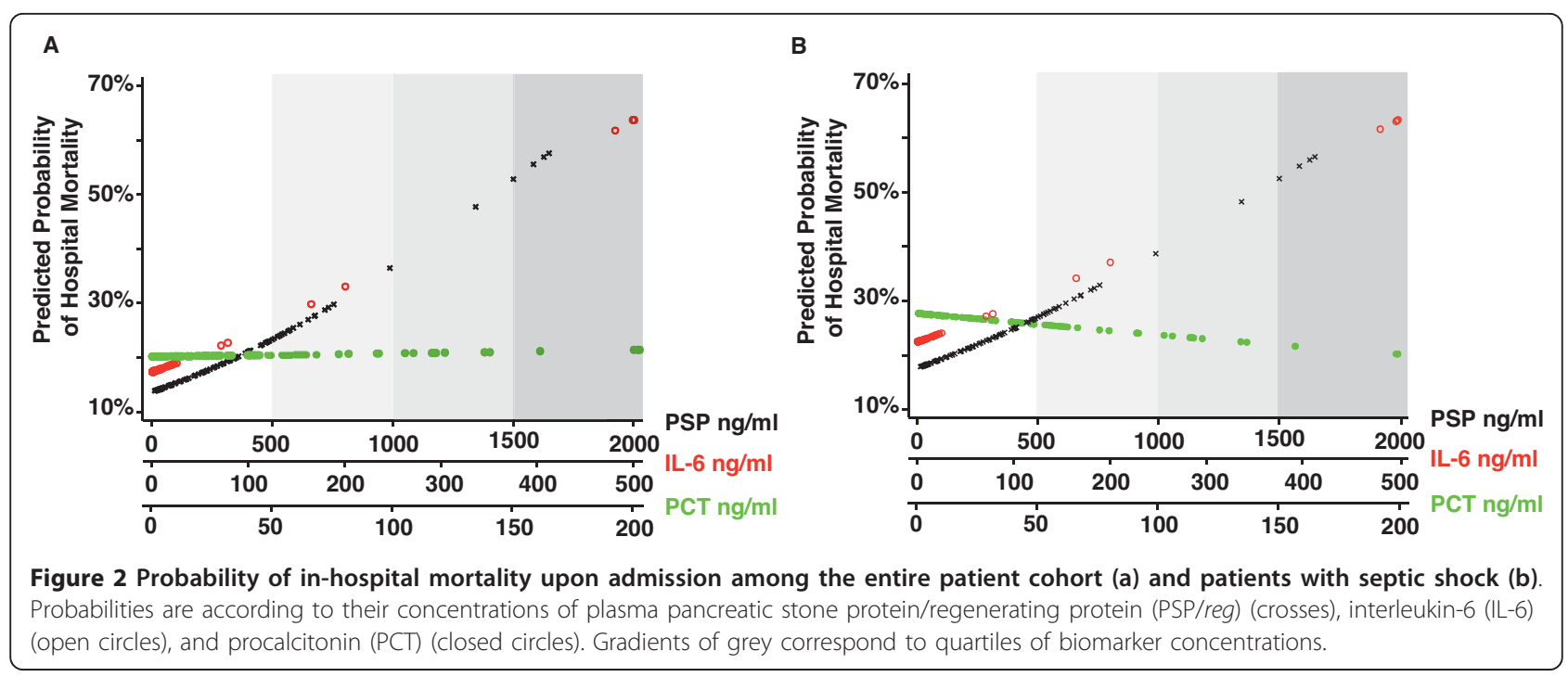

$\mathrm{PSP} /$ reg over the currently available predictors of disease evolution, such as cytokines, may be its presence in the plasma of all septic patients at the time of ICU admission. This sharply contrasts with the pro-inflammatory cytokines tumor necrosis factor-alpha, IL-1, and IL-6, which showed very good predictive values in dedicated trials $[30,31]$ but whose use in daily life was finally hampered by their short window of expression in plasma, making them difficult to interpret at the bedside in a population of patients in whom the time between the onset of sepsis and the blood test cannot be standardized [32].

The strength of our study is that it is representative of the usual population of patients admitted to a mixed ICU. Inclusion criteria were simple, making the setting correspond to what any clinician could encounter in his or her daily practice, increasing the chances of $\mathrm{PSP} /$ reg measurement implementation at the bedside to predict patient outcome. The small number of patients may explain the absence of a correlation of APACHE II or SAPS II with mortality in a cohort of patients with severe infections [33]. In this context, the strong association of PSP/reg with mortality might be viewed as indirect evidence of its better specificity for sepsis. The fact that stratification of patients with sepsis could occur within 24 hours of admission would eventually exclude from stratification most patients without a clear diagnosis of sepsis (this strategy resulted in a low number of non-documented infections in our study) as well as those dying rapidly despite resuscitation and for whom very early evaluation of prognosis ( $<18$ hours) would probably not result in a different initial management [1].

This single-center study also has several limitations. First, since 18 (10\%) patients died before consent could be obtained, selection bias cannot be excluded. This may also have contributed to the lower mortality rate of our patients with septic shock compared with rates reported earlier [2-4]. Second, owing to organizational constraints, patient recruitment was restricted to periods when coinvestigators worked as attending physicians. Third, since the purpose of the study was to explore the accuracy of $\mathrm{PSP} /$ reg compared with that of other commonly used or studied predictors (such as pro-inflammatory cytokines) in a homogenous population of patients with a definite diagnosis of sepsis at the time of ICU admission and not between populations of septic and non-septic patients, patients without sepsis were not included. This may have resulted in an apparently modest absolute predicting power (ROC of 0.65 ). Finally, owing to the relatively small number of patients, these results require further validation in a larger and preferentially multicentric cohort of patients with sepsis.

Though preliminary, our data still suggest that PSP/reg determination could be useful in the stratification of patients with septic shock. After initial resuscitation, PSP/ reg blood levels that are measured within 24 hours of ICU admission may help to detect patients at high risk of death and to reduce the number of those susceptible to receive new and costly adjunctive treatments, such as specific immunotherapy [34], anti-cytokines [35], or extra-corporeal lipopolysaccharide removal [36].

\section{Conclusions}

We conclude that a single measurement of PSP/reg concentration within 24 hours of ICU admission stratifies patients with sepsis according to severity of infection and risk of death. If our findings are confirmed by further studies, this promising biomarker may help physicians to tailor treatments to individual patients according to risk of death. 


\section{Key messages}

- Commonly used biomarkers, such as C-reactive protein and procalcitonin, are insufficiently sensitive or specific to stratify patients with sepsis.

- Pancreatic stone protein/regenerating protein (PSP/reg) is an accurate biomarker to stratify septic patients admitted to intensive care units (ICUs).

- PSP/reg blood measurement within 24 hours of ICU admission predicts risk of death more accurately than procalcitonin and pro-inflammatory cytokines.

- PSP/reg may help to identify, among all patients admitted for sepsis, those most susceptible to benefit from aggressive management.

\section{Additional material}

Additional file 1: Supplemental methods: Definition of sepsis, of infections, of organ dysfunction, of microbiological detection and identification. Method for measurement of plasma biomarker concentrations [15,37,38]. Table S1: Plasma concentrations of biomarkers of sepsis and severity scores in patients with septic shock. Table S2: Biomarkers and severity score performances (area under the curve [AUC] values) predicting in-hospital mortality in the entire population of patients with sepsis (ALL) and in the subgroup of patients with septic shock (Septic Shock Patients).

Additional file 2: Figure S1: Study flow chart.

Additional file 3: Figure S2: Plasma concentrations and medians (dashed lines) of acute phase proteins (Panel A) and proinflammatory cytokines (Panel B) within $24 \mathrm{~h}$ of ICU admission among 107 patients admitted for severe sepsis $(n=33)$ and septic shock $(n=74)$.

Additional file 4: Figure S3: Plasma concentrations of PSP/reg in patients admitted for severe burns, for severe sepsis and septic shock, respectively (Box plot: median, 25th and 75th percentiles, min, max. Diamond: mean value).

\section{Abbreviations}

APACHE II: Acute Physiology and Chronic Health Evaluation II; AUC: area under the curve; Cl: confidence interval; CRP: C-reactive protein; ICU: intensive care unit; IL: interleukin; IQR: interquartile range; OR: odds ratio; PCT: procalcitonin; PSP/reg: pancreatic stone protein/regenerating protein ROC: receiver operating characteristic; SAPS: Simplified Acute Physiology Score; SD: standard deviation; SOFA: Sequential Organ Failure Assessment.

\section{Acknowledgements}

We thank Laurence Leone for outstanding technical assistance and the members of the Lausanne Sepsis Group - Anne Angelilo-Scherrer, Jacques Bille, Philippe Jolliet, Philippe Moreillon, Guy Prod'hom, Thierry Roger, and Pierre-Yves Bochud - for their constructive support. This study was funded by an unrestricted grant from the 'Loterie Romande' and the 'Fondation pour la Recherche en Soins Intensifs'. Y-AQ is supported by Swiss National Science Foundation (SNF)/Swiss Medical Association (FMH) grant PASMP3123226 and a grant from the SICPA Foundation. LL is supported by the SNF (grants 32000-118174/1 and 310030-135394/1). IG is supported by an SNF grant (SNF 33CM30-124087/1). TC is supported by grants from the SNF (310030-118266), the Leenaards Foundation, and the Santos-Suarez Foundation for Medical Research.

\section{Author details}

${ }^{1}$ Department of Intensive Care Medicine, University Hospital Medical Center (CHUV) and University of Lausanne, Rue du Bugnon 46, CH-1011 Lausanne, Switzerland. ${ }^{2}$ Community Prevention Unit, Institute of Social and Preventive
Medicine, University Hospital Medical Center (CHUV) and University of Lausanne, Route de la Corniche 10, $\mathrm{CH}-1010$, Switzerland. ${ }^{3}$ Unit of Population Epidemiology, Division of Primary Care Medicine, Department of Community Medicine, Primary Care, and Emergency Medicine, Geneva University Hospitals, Geneva, Rue Gabrielle-Perret-Gentil 4, CH-1211, Geneva 14, Switzerland. ${ }^{4}$ Swiss Hepato-Pancreatico-Biliary Center, Department of Visceral and Transplant Surgery, University Hospital, Raemistrasse 100, CH8091 Zürich, Switzerland. ${ }^{5}$ Infectious Diseases Service, University Hospital Medical Center (CHUV) and University of Lausanne, Rue du Bugnon 46, CH1011 Lausanne, Switzerland.

\section{Authors' contributions}

$Y-A Q, I G, T C, L L$, and $P E$ were involved in the conception and design of the study, analyzed the data, and wrote the paper. FD collected and analyzed the data. MB and RG measured PSP/reg in blood samples and contributed to the analysis and interpretation of data. All authors read and approved the final manuscript.

\section{Competing interests}

RG is the inventor of a patent that is owned by the University of Zurich and that is for the use of PSP as a 'method for assaying sepsis in humans'. The other authors declare that they have no competing interests.

Received: 21 January 2012 Revised: 26 April 2012

Accepted: 2 July 2012 Published: 2 July 2012

\section{References}

1. Dellinger RP, Levy MM, Carlet JM, Bion J, Parker MM, Jaeschke R, Reinhart K, Angus DC, Brun-Buisson C, Beale R, Calandra T, Dhainaut JF, Gerlach H, Harvey M, Marini JJ, Marshall J, Ranieri M, Ramsay G, Sevransky J, Thompson BT, Townsend S, Vender JS, Zimmerman JL, Vincent JL: Surviving Sepsis Campaign: international guidelines for management of severe sepsis and septic shock: 2008. Crit Care Med 2008, 36:296-327.

2. Bernard GR, Vincent JL, Laterre PF, LaRosa SP, Dhainaut JF, LopezRodriguez A, Steingrub JS, Garber GE, Helterbrand JD, Ely EW, Fisher CJ Jr: Efficacy and safety of recombinant human activated protein $\mathrm{C}$ for severe sepsis. N Engl J Med 2001, 344:699-709.

3. Vincent JL, Sakr Y, Sprung CL, Ranieri VM, Reinhart K, Gerlach H, Moreno R, Carlet J, Le Gall JR, Payen D: Sepsis in European intensive care units: results of the SOAP study. Crit Care Med 2006, 34:344-353.

4. Vincent JL, Rello J, Marshall J, Silva E, Anzueto A, Martin CD, Moreno R, Lipman J, Gomersall C, Sakr Y, Reinhart K: International study of the prevalence and outcomes of infection in intensive care units. JAMA 2009, 302:2323-2329.

5. Calandra T, Glauser MP, Schellekens J, Verhoef J: Treatment of gramnegative septic shock with human IgG antibody to Escherichia coli J5: a prospective, double-blind, randomized trial. J Infect Dis 1988, 158:312-319.

6. Abraham E, Anzueto A, Gutierrez G, Tessler S, San Pedro G, Wunderink R, Dal Nogare A, Nasraway S, Berman S, Cooney R, Levy H, Baughman R, Rumbak M, Light RB, Poole L, Allred R, Constant J, Pennington J, Porter S: Double-blind randomised controlled trial of monoclonal antibody to human tumour necrosis factor in treatment of septic shock. NORASEPT II Study Group. Lancet 1998, 351:929-933.

7. Opal S, Laterre PF, Abraham E, Francois B, Wittebole X, Lowry S, Dhainaut JF, Warren B, Dugernier T, Lopez A, Sanchez M, Demeyer I, Jauregui L, Lorente JA, McGee W, Reinhart K, Kljucar S, Souza S, Pribble J: Recombinant human platelet-activating factor acetylhydrolase for treatment of severe sepsis: results of a phase III, multicenter, randomized, double-blind, placebo-controlled, clinical trial. Crit Care Med 2004, 32:332-341.

8. Hotchkiss RS, Karl IE: The pathophysiology and treatment of sepsis. N Engl J Med 2003, 348:138-150.

9. Opal SM: Clinical trial design and outcomes in patients with severe sepsis. Shock 2003, 20:295-302.

10. Vincent JL, Donadello K, Schmit X: Biomarkers in the critically ill patient: C-reactive protein. Crit Care Clin 2011, 27:241-251.

11. Marshall JC, Reinhart K: Biomarkers of sepsis. Crit Care Med 2009, 37:2290-2298.

12. Tang BM, Eslick GD, Craig JC, McLean AS: Accuracy of procalcitonin for sepsis diagnosis in critically ill patients: systematic review and metaanalysis. Lancet Infect Dis 2007, 7:210-217. 
13. Graf R, Schiesser M, Reding $T$, Appenzeller P, Sun LK, Fortunato F, Perren A, Bimmler D: Exocrine meets endocrine: pancreatic stone protein and regenerating protein-two sides of the same coin. J Surg Res 2006, 133:113-120

14. Keel M, Harter L, Reding T, Sun LK, Hersberger M, Seifert B, Bimmler D, Graf R: Pancreatic stone protein is highly increased during posttraumatic sepsis and activates neutrophil granulocytes. Crit Care Med 2009, 37:1642-1648.

15. Delodder F, Liaudet L, Que YA, Lajaunias F, Graf R, Bain M, Moreillon P, Roger T, Calandra T, Eggimann P, the Lausanne Sepsis Network: Pancreatic Stone Protein (PSP): A Biomarker Of Sepsis. Paper presented at: 50 th Interscience Conference on Antimicrobial Agents and Chemotherapy; 12-15 Sept. 2010; Boston, MA, USA, Abstract L1-1018.

16. Levy MM, Fink MP, Marshall JC, Abraham E, Angus D, Cook D, Cohen J, Opal SM, Vincent JL, Ramsay G: 2001 SCCM/ESICM/ACCP/ATS/SIS International Sepsis Definitions Conference. Crit Care Med 2003, 31:1250-1256.

17. McCabe W, Jackson G: Gram-negative bacteremia. Arch Intern Med 1962, 110:847-855.

18. Le Gall JR, Lemeshow S, Saulnier F: A new Simplified Acute Physiology Score (SAPS II) based on a European/North American multicenter study. JAMA 1993, 270:2957-2963.

19. Moreno RP, Metnitz PG, Almeida E, Jordan B, Bauer P, Campos RA, lapichino G, Edbrooke D, Capuzzo M, Le Gall JR: SAPS 3-From evaluation of the patient to evaluation of the intensive care unit. Part 2 Development of a prognostic model for hospital mortality at ICU admission. Intensive Care Med 2005, 31:1345-1355.

20. Knaus WA, Draper EA, Wagner DP, Zimmerman JE: APACHE II: a severity of disease classification system. Crit Care Med 1985, 13:818-829.

21. Vincent JL, Moreno R, Takala J, Willatts S, De Mendonca A, Bruining H, Reinhart CK, Suter PM, Thijs LG: The SOFA (Sepsis-related Organ Failure Assessment) score to describe organ dysfunction/failure. On behalf of the Working Group on Sepsis-Related Problems of the European Society of Intensive Care Medicine. Intensive Care Med 1996, 22:707-710.

22. Berger MM, Baines M, Raffoul W, Benathan M, Chiolero RL, Reeves C, Revelly JP, Cayeux MC, Senechaud I, Shenkin A: Trace element supplementation after major burns modulates antioxidant status and clinical course by way of increased tissue trace element concentrations. Am J Clin Nutr 2007, 85:1293-1300.

23. Unno M, Nata K, Noguchi N, Narushima $Y$, Akiyama T, Ikeda T, Nakagawa $K$, Takasawa S, Okamoto H: Production and characterization of Reg knockout mice: reduced proliferation of pancreatic beta-cells in Reg knockout mice. Diabetes 2002, 51(Suppl 3):S478-483.

24. Senegas-Balas FO, Figarella CG, Amouric MA, Guy-Crotte OM, Bertrand CA, Balas DC: Immunocytochemical demonstration of a pancreatic secretory protein of unknown function in human duodenum. J Histochem Cytochem 1991, 39:915-919.

25. Fukui H, Kinoshita Y, Maekawa T, Okada A, Waki S, Hassan S, Okamoto H, Chiba T: Regenerating gene protein may mediate gastric mucosal proliferation induced by hypergastrinemia in rats. Gastroenterology 1998 115:1483-1493.

26. Graf R, Schiesser M, Lussi A, Went P, Scheele GA, Bimmler D: Coordinate regulation of secretory stress proteins (PSP/reg, PAP I, PAP II, and PAP III) in the rat exocrine pancreas during experimental acute pancreatitis. $J$ Surg Res 2002, 105:136-144.

27. Harbarth S, Holeckova K, Froidevaux C, Pittet D, Ricou B, Grau GE, Vadas L, Pugin J: Diagnostic value of procalcitonin, interleukin-6, and interleukin-8 in critically ill patients admitted with suspected sepsis. Am J Respir Crit Care Med 2001, 164:396-402.

28. Angus DC: The search for effective therapy for sepsis: back to the drawing board? JAMA 2011, 306:2614-2615.

29. Boeck L, Graf R, Eggimann P, Pargger H, Raptis DA, Smyrnios N, Thakkar N, Siegemund M, Rakic J, Tamm M, Stolz D: Pancreatic stone protein: a marker of organ failure and outcome in ventilator associated pneumonia. Chest 2011, 140:925-932.

30. Calandra T, Baumgartner JD, Grau GE, Wu MM, Lambert PH, Schellekens J, Verhoef J, Glauser MP: Prognostic values of tumor necrosis factor/ cachectin, interleukin-1, interferon-alpha, and interferon-gamma in the serum of patients with septic shock. Swiss-Dutch J5 Immunoglobulin Study Group. J Infect Dis 1990, 161:982-987.
31. Calandra T, Gerain J, Heumann D, Baumgartner JD, Glauser MP: High circulating levels of interleukin- 6 in patients with septic shock: evolution during sepsis, prognostic value, and interplay with other cytokines. The Swiss-Dutch J5 Immunoglobulin Study Group. Am J Med 1991, 91:23-29.

32. Pierrakos C, Vincent JL: Sepsis biomarkers: a review. Crit Care 2010, 14:R15.

33. Baumgartner JD, Bula C, Vaney C, Wu MM, Eggimann P, Perret C: A novel score for predicting the mortality of septic shock patients. Crit Care Med 1992, 20:953-960.

34. Lu Q, Rouby JJ, Laterre PF, Eggimann P, Dugard A, GiamarellosBourboulis EJ, Mercier E, Garbino J, Luyt CE, Chastre J, Georgescu-Kyburz V, Rudolf MP, Gafner V, Lazar H, Koch H, Perez A, Kramer SD, Tamm M: Pharmacokinetics and safety of panobacumab: specific adjunctive immunotherapy in critical patients with nosocomial Pseudomonas aeruginosa 011 pneumonia. J Antimicrob Chemother 2011, 66:1110-1116.

35. Rice TW, Wheeler AP, Morris PE, Paz HL, Russell JA, Edens TR, Bernard GR: Safety and efficacy of affinity-purified, anti-tumor necrosis factor-alpha, ovine fab for injection (CytoFab) in severe sepsis. Crit Care Med 2006, 34:2271-2281.

36. Cruz DN, de Cal M, Piccinni P, Ronco C: Polymyxin-B hemoperfusion and endotoxin removal: lessons from a review of the literature. Contrib Nephrol 2010, 167:77-82.

37. Bizzini A, Durussel C, Bille J, Greub G, Prod'hom G: Performance of matrixassisted laser desorption ionization-time of flight mass spectrometry for identification of bacterial strains routinely isolated in a clinical microbiology laboratory. J Clin Microbiol 2010, 48:1549-1554.

38. Bone RC, Sibbald WJ, Sprung CL: The ACCP-SCCM consensus conference on sepsis and organ failure. Chest 1992, 101:1481-1483.

\section{doi:10.1186/cc11406}

Cite this article as: Que et al:: Pancreatic stone protein as an early biomarker predicting mortality in a prospective cohort of patients with sepsis requiring ICU management. Critical Care 2012 16:R114.

\section{Submit your next manuscript to BioMed Central and take full advantage of:}

- Convenient online submission

- Thorough peer review

- No space constraints or color figure charges

- Immediate publication on acceptance

- Inclusion in PubMed, CAS, Scopus and Google Scholar

- Research which is freely available for redistribution

Submit your manuscript at www.biomedcentral.com/submit
C) Biomed Central 